\title{
An Analysis of Problems of Culture Guided in the Process of English Major Teaching
}

\author{
Hongbin Dai \\ Xiamen University, \\ Xiamen, China \\ dhb9608@163.com
}

\author{
Xiying Liu* \\ Central China Normal University \\ Wuhan, China \\ Longlongw@126.com
}

\begin{abstract}
Culture plays a crucial part in language teaching. This paper discusses the importance of imparting culture knowledge to students in the process of teaching English. It mainly concentrates on the contents of the culture to be guided in, the guiding methods as well as the guiding principles that need to be adhered to. It is really a great challenge for professors to improve students' language qualifications and meanwhile improve their cultural abilities, but it deserves their efforts. Only by improving students' cultural abilities can professors develop students' sensibilities of cultural differences, forbearance, and flexibilities to deal with cultural differences.
\end{abstract}

Keywords_English teaching; The culture guided in; English majors; Principles

\section{INTRODUCTION}

The relationship between culture and language is gradually receiving attention from the public. The scholars both at home and abroad tend to discuss culture as well as language in detail. They always do so by closely connecting and comparing the two related issues. Sapir, the well-known American linguist, wrote in Language that language would not have existed without culture, and further elaborated on their relationship in the book by stating that culture could be explained as the actions and thoughts of the society, while language the concrete expression of ideas [1]. Byram, the British linguist, holds the view that the acquisition of language brings leaners that of culture at the same time [2]. The Syllabus of English Majors in Higher Education, which was published in May, 2000, pointed out that English majors in higher education aimed at cultivating talents in the comprehensive sense that have solid foundation of English language skills, extensive knowledge of cultures, and the ability to apply English in various fields, such as diplomacy, education, and economy and trade, through the work of translation, teaching, management, and researching [3]. It is also in the teaching requirements of this syllabus that the idea how talents in fields of English must transcend the practical skills of listening, speaking, reading, writing and translating, and be equipped with relatively high cultural literacy. To know about culture helps to improve one's communicative competence and grammatical competence, “... a normal child acquires knowledge of sentences, not only as grammatical, but also as appropriate" [4]. It is also in the teaching requirements of this syllabus that the idea how talents in fields of English must transcend the practical skills of listening, speaking, reading, writing and translating, and be equipped with relatively high cultural literacy. In the syllabus of foreign language teaching, formulated by American Council on the Teaching of Foreign Languages, social and cultural competence is officially listed as the fifth practical language skill following listening, speaking, reading and writing. It is well demonstrated above that the relationship between culture and language is gradually receiving more attention from the public. Therefore, how to impart culture into English language teaching is considered as something particularly crucial. Only when the aim of culture imparting is arrived at can professors boast of their active roles in the teaching process of English majors.

\section{CONTENT OF CULTURE IMPARTING}

It is universally acknowledged that culture is an allembracing concept, which includes people's values, achievements in literature, art and science, customs, lifestyles, social organizations, their language, and some related nonverbal communicative method, such as body language. Imparting cultural contents to English teaching has long been considered as a difficult but worthwhile project. From the perspectives of English teaching, the cultural content must include both the macroscopic and microscopic cultural knowledge. At the beginning stage of English teaching, it is advisable to brief the fundamental elements in cultures to the students as a theoretical and macroscopic introduction to the language study. During the following teaching process, the teachers are suggested to refer to theories in analyses of the microscopic cultural knowledge, and consequently note the cultural similarities and differences on the theoretical level. Over the long time, the students will form a macroscopic and comprehensive concept of the English culture, learn to analyze questions from the aspect of the English culture, and obtain a further understanding of culture. Cultural content contains both macroscopic and macroscopic content.

Macroscopic Cultural Content is related to diverse factors, such as values and ways of thinking. In order to have a comprehensive and correct idea of cultures, it is necessary to learn about values and ways of thinking from the perspective of cultures.

1. Values, the core issue of culture, include various contents. More specifically, firstly, the worldview is involved. British and American embrace distinguishing mankind from heaven, which enables them to actively transform and conquer nature. 
Chinese people, however, inherit the traditional worldview of oneness of Heaven and Man, which shows the respect and worship towards nature. Secondly, individual-based thinking and ethic-based thinking are also important matters. Individuality is emphasized in Britain and America, where the right to privacy is respected so that there is a clear demarcation concerning personal wealth. Chinese people, on the contrary, pay tremendous attention to ethic-based thinking, also known as collectivism. The collective is highly valued by Chinese people in that not damaging the collective interests is considered as the premise of what they say or do, and ignoring personal benefits advocated. Thirdly, it comes to the power of legislation and exemplars. British and American cultures focus more on the methods to efficiently and effectively refrain people from becoming corrupted, while the traditional Chinese culture pays close attention to the ways to educate people. In other words, the former rules are by law, while the latter educates through emotions. Fourthly, the concept of time should be dealt with in a good way. On the one hand, the British and American people look forward to the future, and do not hold dead tight on the current situation. However satisfying the current situation might be, they are never content with the things as they are, but instead, put efforts into making changes in a way that will improve the future. On the other hand, the past is stressed by the Chinese people who expect to obtain experience from the past successes or lessons from failures. Lastly, it also concerns playing it safe or striving for changes. The British and American people love seeing norms broken and changes made, while Chinese people propose survival in stability and happiness from a contented mind.

2. The ways of thinking usually vary. Firstly, narrations and illustrations in English customarily follow the rule of starting from the small issue to the large issue, from the specific to the general, and from the individual to the whole. Chinese, however, follows the opposite rule. For example, as is well demonstrated in the sentence that "Shanghai is one of the biggest cities in the world", the British and American people start a conversation with the central interest of a specific issue-"one of...” In contrast, as can be inferred from the Chinese version of the sentence "Shanghai is one of the biggest cities in the world", Chinese people form the habit of beginning from the big issue-world, and reflecting on the small clues, starting from the whole picture, which encourages them to propel a discussion from the international to the domestic and from the domestic to the specific unit or organization. Another instance is that, when it comes to time, Chinese people follow the sequence of year, month, day, and hour; concerning places, the sequence consists of country, province, city, town, and other small units in order. British and American people, however, adopt the opposite order, namely, they start from the month or day, and then proceed to the year. Secondly, there is the emphasis people lay on the unknown issues or the known issues. In a sentence including both known and unknown things, the British and American people normally start with the unknown and end with the known. For example, they usually ask the question, "Where are you going", to inquire for more information about a person's plans. To the opposite, the word order in the same question changes into " you are going where?” in Chinese, to fulfill the same purpose. Thirdly, there is the difference of abstract thinking and emotional thinking.
The popular use of nouns in English sheds a light on the British and American people's tendency of transforming the specific to the abstract. Contrarily, Chinese people are fond of verbs and pay close attention to specification, which remain one of the characteristics of emotional thinking. In conclusion, the different ways of thinking in English and Chinese demonstrate the ego-centrism for the English speaking people and grouporientation for the Chinese people.

Microscopic cultural content concerns more specific aspects. They are as follows: culture knowledge, cultural factors that interfere with communication but do not reflect themselves in language, cultural meanings of vocabulary, discourse, text structure, and cultural meaning of non-verbal communication, etc.

1. Culture Knowledge mainly touches upon economy, politics, history, geography, literature, art and other related disciplines. Based on the fact that the majority of the students have had some basic ideas of the subjects mentioned above, the teachers are suggested to introduce the related common senses and knowledge if necessary. For example, introductions to the developing status of the productive forces, the current situation of science and technology, and the masterpieces in literature and art are usually recommended. Of course, this requires the professor to have rich culture knowledge and to be able to follow the developing cadence of the times.

2. Cultural factors that interfere with communication but do not reflect themselves in language includes social norms and customs which people have to conform to; for instance, addresses, greetings, inquiries, apologies, acknowledgements, farewells, and phone calls. When it comes to this, basing the analysis of a specific issue on the brief retrospect of the values and thinking patterns in the macro-culture tend to better students' memory of and comprehension of culture and help them to learn what is important, therefore making it worthwhile to get a thorough idea of macro-culture related contents before people come to some micro-culture subjects.

3. In terms of the cultural meanings of vocabulary, Wilkins proposes that without grammar, expression can hardly be well conveyed, and without words, nothing can be articulated. [5] Words play an indispensable role in English learning, and they are considered to be the essential components of cultural introduction. Words originate from many sources. There are Words from Greek mythology, the Bible, literary works, historical events and social customs and manners, such as Achilles' heels (the only fatal weakness), a Pandora's box (the source of disaster and trouble), a Herculean task (an arduous task), an Uncle Tom (a resigned person), a catch-22 situation (a dilemma). There are also with roughly the same basic meanings but contrasting derived meanings in English and Chinese. Besides the meaning of "tale" in English, the word "story" also has the meaning of "news" "event" "tradition" and so forth. There are words with different meanings in different cultures. The word "propaganda" in English contains negative meaning, which serves as a contrast to its meaning in Chinese. Similarly, words like "politician" "community" "blue room" have their own meanings in a given culture. There are words with identical superficial meanings but diverse associative, affective, and metaphorical notions. Western culture associates 
"dragon" with something evil and disastrous, while Chinese culture regards it as the symbol of bravery and very often Chinese consider themselves as the descendants of the dragon. Moreover, in English, "green with eyes" stands for the jealousy, and in contrast, Chinese expression for jealousy is eyes getting red. There are proverbs, idioms, and mottos that reflect certain culture. For example, "hold one's sides with laughter" (laugh heartily), "haste makes waste" (moderate speed), "where there is a smoke, there is a fire" (things happen with reasons).

4. As far as microscopic cultural content is concerned, cultural meanings of discourse is also important. "safe topics" are recommended when you are having the conversation with the westerners. Topics like weather, geography and city situation are welcomed, while personal inquiries like age, salary, religion and political stand should better be avoided. Beating around the bush is not advocated, for westerners are more accustomed to presenting the key issue at the first place in order to attract the listener's very attention.

5. Cultural meaning of the text structure is also an important part of microscopic content. The text structure in English appears to be linear, with the topic sentence firstly stated and followed by further illustrations. On the contrary, Chinese text structure is spiral and has the characteristics of circuity and euphemism. If Chinese students apply the Chinese model to their English writing, the result will be the language in English style but the text structure in Chinese. In this case, westerners may consider the writing illogical. Therefore, the problem of the text structure should be addressed in students' reading and writing.

6. The last, but not the least main part of the microscopic content is the cultural meaning of non-verbal communication. This includes the use of space, physical act (gaze in static or active body movements), vocal behavior, and appearances (dresses, figure, complexion, odor, etc.). It differs a lot in different cultures. Students should be introduced the cultural differences in order for their mutual understandings and efficient communication with westerners.

\section{PRINCIPLES OF CULTURAL INTRODUCTION}

Though we theoretically intend to equate language acquisition and cultural acquisition, very often we attach more importance to the language teaching. Here are some principles that should be adhered to during the teaching process: the principle of practicability, the principle of relativity, and the principle of comprehensiveness.

The principle of practicability requires that contents introduced should be closely related to students' language learning and their daily lives; even they should take their future jobs into consideration. In this way, on the one hand, the culture and language learning will not be complicated and abstract, and on the other, this will arouse their interests for further learning. Once students have initiative, interaction can be achieved and they will make a lot of progress in regard to the culture content.

The principle of relativity requests that contents introduced are supposed to be linked with the teaching material, thus avoiding students' feeling of digression and at the same time gradually achieving the effect of cultural fertilization. Generally speaking, for the English major, teachers often are likely to find the text-related materials. Teachers are also supposed to seek some other materials after class and complement them to the text-related ones, so that students would not feel bored.

The principle of comprehensiveness means that both macro-culture and micro-culture should be considered and the general description of the English culture needs to be presented in order to instruct and analyze specific cultural phenomenon. In this way, students can better comprehend such cultural phenomena, including its causes, and that will motivate them to have more knowledge of different cultures, account for their divergence. As a result, students will have more tolerant attitudes toward those culture phenomena that are sometimes so weird to them.

\section{Means of Culture InTROduction}

Means of cultural introduction follow the discussion of its contents and principles. They include direct illustration, encouragement of students' participation, the use of teaching aids such as the multimedia facilities, induction and comparison, guidance and supervision practice, and having more communications with foreign teachers.

Direct illustration is rather effective in some cases. For the abstract and unfamiliar cultural phenomena, it is better explained in concise and explicit language. For example, "Westminster" can be introduced as the cemetery for the celebrity; comparison between the "continental breakfast" and "English breakfast" can be drawn when comes to the explanation of "breakfast"; and if there is no time limit, teachers can further the topic to table manners and western eating habits to arouse students' interests.

Encouragement of students' participation is another way to help introduce the culture. Student-oriented teaching methods encourage students' "role play", "discussion", "debate", "presentation", "duty report", "vocabulary contest" and "reading contest". During these processes, as the syllabus requires cultivating students' cultural sensitiveness, students' are reminded of their linguistic forms, which should be in accordance with their roles and identities.

The use of teaching aids like pictures, powerpoints, movies, videotapes and multi-medias, which will provide students with the intuitive impressions. Class discussion can follow after the watching of the video. For instance, teachers may instruct on students' opinions of culture from the perspective of values and modes of thinking. Teachers may also ask the students to imitate and perform the dialogue in the video. Of course, professors should make good preparation for it, in order to point out the weaknesses of students' performance, and guide them in a rational way. Therefore, the class atmosphere will be made lively, and the students' initiative will be fully developed. Students will thus be able to learn while entertaining themselves and entertain while learning. In this way, the best is sure to be achieved.

Professors can make specific comparisons and inductions among cultural projects such as dating customs, vacations, non- 
verbal communications, shopping habits, under Chinese and English circumstances, to help have a better understanding of different cultures, and help students to adopt correct and reasonable cognitive modes, in order for them to improve their cross-culture communicative abilities.

Throughout the process of culture introduction, professors' guidance and supervision practice are quite necessary. During the teaching process, it is necessary to teach students the means to acquire cultural knowledge, such as looking up in dictionaries, encyclopedias, magazines and journals, and appreciate literary works, and in the meanwhile recommend or assign afterschool reading materials suitable for students about cultures. It is also a good idea to require students to write reading reports and openly conduct discussions, therefore it can improve them and develop the habits to attach importance to and comprehend cultures, as well as analyze cultures.

One major way to introduce cultures to students is to encourage them to have better and more communications with the foreign professors. To some extent, this is irreplaceable. In daily contact with the foreign professors, students are able to learn what the students can't learn in class. For instance, students may know what they should state on different occasions and what the crucial differences of some synonyms are and how they can adjust to new cultures. All these could be observed only after class. When the students have in mind the task of learning culture while they are with the foreign professors, they will make achievements in a short period. In a word, as long as the students strive to learn things about culture, they will make good use of the time with foreign professors and learn a lot of knowledge while at the same time strengthening their friendship.

\section{CONCLUSION}

As is stated, the introduction of culture plays a very important role in language studies. Different nations have different features. For example, Chinese people are not as straightforward as the Americans. "Americans are very direct people" [6]. This presents the professors a challenge. They have to improve students' language qualifications and at the same time improve their cultural abilities as well as enrich professors' own cultural knowledge. What's more, during the teaching, it should be made clear that the main purpose of cultural teaching is to improve language standards and communicative abilities. Only by doing so can they develop students' sensibilities of cultural differences, forbearances, and flexibilities to deal with cultural differences.

\section{REFERENCES}

[1] E. Sapir, Language: An Introduction to the Study of Speech, New York: Harcourt, Brace\&Company, 1921, pp. 3-5.

[2] M. Byram, Culture Studies in Foreign Language Education, Celvedon: Multilingual Matters, 1989, p. 36.

[3] Syllabus for English Majors of Universities. Shanghai: Shanghai Foreign Language Teaching Press, 2000, p. 4.

[4] L. Loveday, The Sociolinguistics of Learning and Using a Non-Native Language, Headington Hill: Pergamon Press Ltd., 1982, p. 60.

[5] D. A. Wilkins, Linguistics in Language Teaching, Edward Ltd, 1972, p. 20.

[6] N. Woronov, and Chi Yunfang, Modern American English: Living and Learning in The West, Shanghai Foreign Language Education Press, p. 13 